(С) И.В. Богдашина

\title{
ИНТИМНЫЕ ПЕРЕЖИВАНИЯ В ЖЕНСКИХ ЭГО-ДОКУМЕНТАХ 1950-1960-Х ГОДОВ: НОВОЕ И ТРАДИЦИОННОЕ В МОДЕЛЯХ СЕКСУАЛЬНОГО ПОВЕДЕНИЯ ПРОВИНЦИАЛЬНЫХ СОВЕТСКИХ ГОРОЖАНОК*
}

\begin{abstract}
В статье изучень взаимоотночения жительниц и жителей крупного, но нестоличного г. Волгограда (Сталинграда) в 1950-1960-е г2. Цель исследования заключается в выявлении поведенческих черт горожанок в сфере межличностных отношений с противоположным полом на основе привлечения материалов эго-документов. Методология исследования базируется на применении метода эмпатии, а также сравнительно-исторического и биографического методов. Источниковую базу исследования составляют материаль эго-документов (дневники, письма, устная история), периодической печати (журналь, газетьл), научно-популярной литературы (брошюры, пособия), нормативно-правовых актов (указы, постановления). в статье раскрыты представления горожанок об интимной жизни, которые они в изучаемый период нередко скрывали от общественности. Власти исподволь вмешивались в семейную жизнь горожан, формируя сексуальную культуру населения. Низкая грамотность женщин в вопросах полового воспитания имела множество последствий (внебрачньле беременности, высокая абортируемость, многодетность). Все еще нередким явлением в браке было неподобающее поведение мужей (пьянство, грубость, измены), а публичность бракоразводного прочесса являлась своеобразныли препятствием на пути разводящихся супругов. Потому в партийных органах не только женщины, но и мужчины видели рычаги давления, при помощи которых можно было разрешить семейные неурядицы. Несмотря на кажушуюся вольность в поведении послевоенного поколения, преобладающим оставался уклад, согласно которому интимная жизнь продолжала скрываться от общественности. Обсуждение «запретных тем» в средствах массовой информации являлось лишь методом на пути нравоучительного воспитания во многом именно женской половины населения. Однако условия прожсивания в нестоличном городе, который с опозданием принимал передовые идеи (важность полового воспитания), вносили немало коррективов в жизни горожанок.
\end{abstract}

Ключевые слова: отношения полов, гендерная антропология, интимные бытовые практики, хрущевская «оттепель», Волгоград

Богдашина Ирина Владимировна - аспирант, Волгоградский государственный университет (400062 Волгоград, Университетский просп., 100), Институт этнологии и антропологии им. Н.Н. Миклухо-Маклая РАН (119991 Москва, Ленинский просп., 32а). Эл. почта: ira18bogdashina@mail.ru

*Подготовлено по плану НИР ИЭА РАН и проекту РФФИ № 19-09-00191 «Женская социальная память как консолидирующий потенциал многопоколенной семьи, укрепления государственности и российской нации (18-21 век)» 
Для цитирования: Богдашина И.В. Интимные переживания в женских эго-документах 1950-1960-х годов: новое и традиционное в моделях сексуального поведения провинциальных советских горожанок // Вестник антропологии, 2021. № 4. C. 174-190.

Взаимоотношения женщин и мужчин в период хрущевской «оттепели» претерпели немало изменений, ведь именно тогда частично были разрушены тоталитарные модели семейно-брачных отношений и сексуального поведения (Кон 2010: 66). Актуальным представляется изучение пересечений и столкновений частной и публичной сфер в повседневной жизни мужчин и женщин. Несмотря на переход властной политики от полного отрицания к попыткам регулирования сексуальной культуры (отмена запрещения абортов, выпуск специализированной научно-популярной литературы), в реальной действительности данная тема, вероятно все еще продолжала оставаться для женщин запретной и сугубо интимной (Сборник законов 1956: 402; За здоровый быт 1956; За здоровый быт 1960; Гранат 1965; Никончик 1965). Именно потому привлечение не только общедоступных источников (нормативно-правовые акты, средства массовой информации), но и материалов эго-документов (письма, дневники, устная история) позволяет реконструировать чувственно-эмоциональную сторону частной, нередко интимной жизни горожанок региона.

Цель исследования - путем анализа материалов эго-документов выявить поведенческие черты горожанок нестоличного региона в сфере межличностных отношений с противоположным полом в условиях частичного разрушения тоталитарной модели брачно-семейных связей и сексуального поведения. Изучение данного аспекта позволит не только выяснить восприятие самими женщинами вопросов сексуальности, но и сопоставить диктуемые нормы с повседневной действительностью нестоличного региона.

Вплоть до 1990-х гг. в отечественной историографии исследований советских женских интимных практик и сексуальности не проводилось, в особенности малоизученными представляются практики нестоличных городов страны. Хотя первые исследования относятся еще к 1960-м гг., большинство из них носили сугубо научный, а не просветительский характер (Кон 1966; Голод 1969; Шевченко 1969; Богданович 1969). Весомый вклад в изучение сексуальной культуры внес социолог С.И. Голод, многие исследовательские изыскания которого не были одобрены советской властью (Кон 2010: 98-99). Потому первые работы отечественных социологов и историков (С.И. Голод, И.С. Кон, Н.Л. Пушкарева), посвященные сексуальной культуре в России и вопросам феминологии начали появляться лишь в 1990-е гг. (Кon 1993; Голод 1996; Кон 1997; Голод 1998; Пушкарева 1998). в 2000-е гг. учеными с разных сторон была изучена модель гендерного уклада и сексуальности (Темкина 2001; Пушкарева 2002; Здравомыслова, Темкина 2003; Темкина 2009). в последнее десятилетие вопросы сексуальной культуры периода десталинизации были затронуты в трудах Н.Б. Лебиной, Т.П. Емельяновой, Н.Л. Пушкаревой, Н.А. Мицюк и других (Лебина 2014; Емельянова 2019; Миненко, Жилянина 2020; Пушкарева, Белова, Мищюк 2021). Однако, вышеупомянутые исследования носят обобщающий характер и специально не рассматривали аспекты взаимоотношений полов в крупном, но нестоличном послевоенном городе на основе привлечения материалов эго-документов.

Период 1950-1960-х гг. характеризовался переменами в быту, а возможность для молодой семьи иметь собственное жилье, приравнивалась к благоприятному разви- 
тию не только семейной, но и интимной жизни. Важным шагом на пути разрешения проблемы жилищного обеспечения стало постановление ЦК КПСС и СМ СССР от 31 июля 1957 г. «О развитии жилищного строительства в СССР», в котором подчеркивалось, что «проблема жилья продолжает оставаться одной из самых острых» (Коммунистическая партия Советского Союза 1986: 195). Несмотря на то, что объем всей жилой площади в регионе в сравнении с 1940 г. к 1966 г. увеличился в 2,5 раза, немногие горожане располагали собственным жильем, удовлетворяющим даже элементарные бытовые потребности (Народное хозяйство 1967: 172). Не только изменение жилищной ситуации, но и попытки медикализации сексуальности, позволили в некоторой мере наладить и стабилизировать сексуальную культуру населения (Кон 2010: 66). Высокие показатели внебольничных абортов, которые к 1950-м гг. достигли своего пика, заставили государство пойти на важный шаг - декриминализировать процедуру; региональные власти сразу же отреагировали на изменения, однако во многом оказались не готовы к проведению программы (Сборник законов 1956: 402; ГАВО: Ф. Р-3969. Д. 165. Л. 175). Перегруженность гинекологических коек, высокий спрос на процедуру, а также смертность от внебольничных абортов оставались насущной проблемой региона на протяжении 1950-1960-х гг. (ГАВО: Ф. Р-3969. Оп. 7. Д. 117. Л. 41, 44-45, 283; Оп. 7. Д. 197. Л. 117; Оп. 11. Д. 34. Л. 193, 282-283; Оп. 11. Д. 56. Л. 81). Потому условия проживания в полностью разрушенном после войны Сталинграде (Волгограде) вносили свои коррективы в личные жизни горожанок.

На наш взгляд, применительно к теме нашего исследования во взаимоотношениях женщин и мужчин можно рассмотреть три периода: добрачные отношения, собственно в браке и на грани (после) распада семьи. Все три блока взаимосвязаны между собой, так как представляют поступательное развитие отношений полов. Важнейшим источником в исследовании выступают эго-документы (дневниковые записи врача-хирурга Зинаиды Сергеевны Седельниковой, устные воспоминания жительниц региона 1932-1960 г.р., а также письма и жалобы личного характера жительниц и жителей в Городской комитет КПСС), которые способны передать отношение самих людей к проблемам межличностного и сексуального поведения, определить соответствие норм общепринятых и тех, которые находили свое место в реальной действительности.

Как уже было сказано, первые исследования в вопросах брака и семьи были предприняты социологами еще в 1960-е гг., тогда ученые отметили, что именно «моральный подход к браку стал преобладающим в советском обществе», однако едва ли передовые взгляды могли иметь широкое распространение в провинциальном городе. Большое значение имело место знакомства будущей пары; согласно опросам, в одном из столичных регионов, именно места проведения досуга (танцы, клуб, каток) являлись самым распространенными местами для знакомства (Харчев 1964: $179,197)$. Об этом вспоминают и опрошенные нами женщины: «Знакомились на танцплощадках, с мужем тоже так познакомилась»; «Знакомились на танцах, танцы все время были, вот на Строителе была танцплощадка, на Судоверфи тоже. На работе у нас было познакомиться невозможно, там были одни женщины» ${ }^{1}$; «Знакомились в основном на танцах. А мы с мужем познакомились в парке, когда гуляли компаниями» (ПМА: И.В.; Л.И.; Л.Д.).

\footnotetext{
${ }^{1}$ Респондентка работала школьной учительницей.
} 
Во многом именно факт свободного общения девушек и юношей в общественных местах формировал культуру отношений между полами на начальном этапе отношений. Кроме того, во многом, «частичная реабилитация личной жизни», которая произошла в 1950-1960-е гг, сыграла ключевую роль в становлении сексуальной культуры уже послевоенного поколения (Пушкарева 2012: 17). Однако в возрождающемся после войны регионе жители нередко сталкивались с культурно-досуговой бедностью, а места публичного досуга не всегда располагали благоприятной обстановкой для знакомства. Некоторые танцплощадки и клубы были оборудованы ненадлежащим образом, о чем в радиопередаче 1960 г. рассказала жительница города: «Оркестр играет плохо. Пять минут играет, а остальное время стоит. Но у нас только одна танцплощадка, а молодежи хочется танцевать. Пора бы позаботиться о том, чтобы танцплощадки у нас были хорошие» (ГАВО: Ф. Р-6174. Оп. 2. Д. 336. Л. 39). Государство всерьез не воспринимало танцплощадки как места знакомства мужчин и женщин, потому как даже здесь можно было ощутить диктуемые правила и нормы: «Подумайте, познакомились люди на танцах, несколько раз встретились - и, пожалуйста, уже семья. Тайком от всех создали семью. Какое может быть счастье, когда все это тайком, когда нужно скрывать от других, когда нужно бояться, чтобы не узнал кто-то, что они вместе, что у них семья уже существует?» - нравоучительным образом рассказывалось в одной из радиопередач для молодежи 1963 г. (ГАВО: Ф. Р-6174. Оп. 2. Д. 451. Л. 291-292). Ведь на таких вечерах нередким было непозволительное поведение юношей, которые навязчиво приставали к девушкам (ГАВО: Ф. Р-6174. Оп. 2. Д. 298. Л. 205; Молодой ленинец 1956: 30 декабря; Молодой ленинец 1958: 5 июля). Возможно, именно потому, представительницы более старшего поколения, предпочитали танцевать в домашней обстановке, в кругу исключительно близких друзей.

В дружеских компаниях врача 3.С. Седельниковой танцы являлись неотьемлемым элементом всех домашних праздничных застолий. Стоит отметить, что в такой обстановке именно танцы выступали самой близкой, подчас сугубо интимной, но открытой формой проявления чувств мужчины и женщины: «Вечер прошел хорошо, музицировали, перепели досыта песен. Чуточку потанцевали. Впервые получила удовольствие в вальсе с ВИ. Даже тихонько поцеловала его в щеку. ВИ в белоснежной из тонкого шелка вьетнамской рубашке, мой подарок, чисто выбритый, покорный и ласковый, снова вернул мне чувства» (ГАВО: Ф. Р-6880. ОП. 6. Д. 26. Л. 168). Безусловно, домашние застолья выступали благоприятными местами знакомства, однако бывало и так, что ситуация выходила за рамки предельно допустимых норм: «С первых минут своего появления, Валентин Павлович уделял слишком много внимания мне, и как узнала позже, просил Давида Павловича помочь ему ближе познакомиться со мной. Однако вряд ли ему был нужен посредник, очень скоро он признался мне в своей симпатии, целовал руки, глубокомысленно смотрел в глаза и даже пытался поцеловать во время танца и в коридоре, преследуя меня до кухни. Такая его активность сразу же оттолкнула меня» - записала с негодованием в дневнике хозяйка дома и организатор застолья, на то время разведенная тридцатичетырехлетняя женщина-врач (ГАВО: Ф. Р-6880. Оп. 6. Д. 15. Л. 122). Тем не менее, в домашнем кругу, где потенциально собирались друзья и знакомые друзей, шансы на доверительное знакомство возрастали. Например, на одном из таких вечеров с помощью друзей, Зинаида Седельникова познакомилась с будущим мужем: «Заходила Татьяна С., проговорилась о том, что много месяцев пыталась познакомить со мной “одного инженера ЗКО”, но не решалась» (ГАВО: Ф. Р-6880. Оп. 6. Д. 22. Л. 155). 
Объединяла будущие пары учеба или работа, если в первом случае знакомства являлись наиболее удачными, то служебные романы не всегда заканчивались успехом: «ГВ вел себя сегодня до крайности молчаливо, глупо, подчеркивая свою обиду. Вот и видна суть человека - словно мальчик, а не муж семейства. Отношение к нему всех клинических незавидное»- высказала замечания Зинаида Седельникова о поведении коллеги, проявляющего к ней излишнее внимание (ГАВО: Ф. Р-6880. Оп. 6. Д. 15. Л. 93). Однако совершенно другую историю рассказала одна из информанток: «Мы с мужем были комсомольскими активистами, познакомились на Судостроительном заводе, он тогда был молодым специалистом, его направили по распределению из г. Горький. Вот так и познакомились на воскреснике, через год поженились. Администрация цеха решила сделать нам комсомольскую свадьбу, проходило мероприятие на Верхней Судоверфи в молодежном клубе. На свадьбу нам подарили ключи от квартиры» (ПМА: Н.П.). Можно сделать вывод о том, что публичные места досуга, в особенности танцевальные вечера, являлись для молодежи не только потенциальным местом знакомства, но и способом найти сексуального партнера (в большей степени для мужчин). С другой стороны, знакомства исключительно в доверительном кругу (зачастую в домашней обстановке), вызывали симпатию у женщин.

Через средства массовой информации власти пытались регулировать сексуальную культуру населения. Преследуя нравоучительные цели, не только женские журналы, газеты и радио, но и специализированная научно-просветительская литература указывали на то, что именно женщина должна нести ответственность за сексуальное поведение себя и партнера. в региональной брошюре «Гигиена женщины», глава под названием «Половая жизнь, гигиена половых сношений» (1-е издание, 1954 г.) не была снабжена какими-либо дополнениями даже спустя 13 лет (3-е издание, 1967 г.). Правильной считалась целомудренность девушки в первую брачную ночь, ведь половая жизнь, естественным путем влекущая за собой беременность, по всем правилам и нормам должна была начаться для женщины только с замужеством (Ананьев 1954; Ананьев 1967: 16-17). Отклонение от нормы строго осуждалось общественностью, например, открыто обсуждали поступок некой Нели, которая в 1963 г. написала в молодежную редакцию радиостудии письмо о помощи. Девушку порицали за то, что она «прожив с юношей без регистрации месяц, оказалась в положении» (ГАВО: Ф. Р-6174. Оп. 2. Д. 451. Л. 288). Указав на легкомысленность девушки, ведущие передачи, вероятно, не брали во внимание факт того, что Неля, как и многие другие девушки региона из-за недостатка знаний в вопросах полового воспитания, была вовсе не осведомлена о нюансах интимной жизни. Однако именно в это время столичные социологи не только обратили внимание, но и признали факт того, что «в советских школах мало занимаются половым воспитанием молодежи», и это совершенно точно соответствовало действительности нестоличного Сталинграда (Волгограда) (Харчев 1964: 201).

Вопросам контрацепции в региональных брошюрах внимание начало уделяться лишь в середине 1960-х гг., однако в таких знаниях женщины нуждались уже давно, ведь проблема искусственного прерывания беременности стояла достаточно остро на протяжении 1950-1960-х гг. (Ананьев 1967: 58; ГАВО: Ф. Р-3969. Оп. 7. Д. 117. Л. 41, 44-45, 283; Оп. 7. Д. 197. Л. 117; Оп. 11. Д. 34. Л. 193, 282-283; Оп. 11. Д. 56. Л. 81). Несмотря на появление специализированной литературы, осведомляющей женщин не только о правилах личной гигиены, вреде аборта, но и способах контрацепции, грамотность женщин в отношении полового воспитания оставалась все еще низкой 
(Коробкевич 1960: 19, 89; Демезер, Дзюба 1956: 10-14; Демезер, Дзюба 1958: 82; Домоводство: 1965: 111). в специальных пособиях для девушек тема взаимоотношений полов также затрагивалась. При этом, нередко подчеркивалось, что «именно от девушки зависит поведение молодого человека» (Коробкевич 1960: 254). Глава под названием «Гигиена брака» заняла прочное место в брошюре «За здоровый быт», впервые вышедшей в 1956 г., однако немногим женщинам региона удавалось прочитать данную книгу, если же таковая появлялась, то сразу вызывала интерес, в особенности со стороны женщин (За здоровый быт 1956: 173; За здоровый быт 1960: 220). в 1956 г. такая книга была и в семье врача Зинаиды Седельниковой, сама женщина, прежде всего как врач, была крайне увлечена новым изданием, отметив, что «давно назрела потребность в подобной литературе... книгу эту читает вся наша квартира» (ГАВО: Ф. Р-6880. Оп. 6. Д. 19. Л. 17). У одной из наших информанток находилась в распоряжении книга «Девочка, девушка, женщина», наличием которой она очень гордилась: «У нас была книга “Девочка, девушка, женщина”, я сама купила, когда была в классе десятом. Все хотели такую книгу, там было любопытно все, раньше же все были святые, не такие как сейчас девушки. Мы ее всем классом читали». Специальную литературу читала и другая респондентка: «Папа привез как-то специальную книгу для девочек, там было все-все написано, с рисунками. Наверное, в классе восьмом я была, вот папа откуда-то привёз эту книгу. С подругами, конечно, обсуждали, обязательно, но эта тема считалась запретной» (ПМА: Е.В.; Л.Д.). Однако многие женщины отметили, что у них такой литературы в распоряжении не имелось (ПМА: О.В.; Т.В.; Г.Ю.; А.И.). Самым распространенным источником информации для них оставались женские журналы, которые выписывались практически каждой семьей, среди них стоит отметить «Работницу» и «Крестьянку», намного реже читали «Советскую женщину». Однако разговоры на интимные темы на страницах этих журналов поднимались нечасто (Добровольский 1953: 25-28; Кононенко 1955: 25; Тарасовой 1962: 21; Карбовская 1962: 26; Стерин 1962: 12-14; Николаева 1962: 28-30).

Практически все опрошенные нами женщины заявили, что они не располагали даже элементарными знаниями в вопросах интимной близости с мужчинами. Респондентки с досадой рассказывают о своем неведении в интимных делах: «Вопросы личной жизни абсолютно не обсуждались, я даже не знаю, почему так, но я совершенно была не подготовлена к замужней жизни, совершенно, хотя я читала все в книге, но на практике получилось, что я не очень поняла все процессы»; «Понятия не имели, понятия не имели про контрацепцию, даже слова этого не знали, ничего. Потом уже между собой, подружками, но очень были наивными и далекими от всего этого» (ПМА: Е.В.; М.Ф.). Такую действительность подтвердила и школьная учительница: «Уроки полового воспитания не проводились, только в 1970-х годах, и то, никто ничего не рассказывал. Девочки погуливали, в 1968 г. девочка родила, учась в десятом классе, я в этом классе работала. Когда я училась в седьмом-восьмом классах, и тогда девочки рожали в школе» (ПМА: Л.И.).

Упоминания о том, что в школах, техникумах и ВУЗах читались лекции на столь необходимые темы, относятся лишь к середине 1960-х гг., однако проблема того, «что юноши и девушки имеют недостаточное представление о личной гигиене, о браке» признавалась; действенной мерой считалось поручение сотрудникам здравоохранения проведение общеобразовательных лекций в учебных заведениях города (Молодой ленинец 1965: 12 января; ГАВО: Ф. Р-3969. Оп. 11. Д. 169. Л. 132). 
Тем не менее, стоит предположить, что едва ли данные мероприятия действительно содействовали повышению уровня грамотности населения в интимных вопросах. Многочисленные аборты на протяжении 1950-1960-х гг., нередко внебольничные (криминальные) оставались самым распространенным способом регулирования рождаемости, что свидетельствует о крайне низкой грамотности женщин всех возрастов о методах контрацепции. Например, в 1952 г. в одной из больниц города наибольшее количество внебольничных абортов приходилось на женщин в возрасте от 20 до 30 лет, что в 2 раза выше, чем в возрастной категории от 30 до 40 лет. Большие очереди на аборты сохранялись и после легализации процедуры, поступательно увеличиваясь с каждым годом. Четверть женщин предпочитали вовсе не указывать причины, подтолкнувшие их на «аборт по желанию», следует предположить, что данный вопрос являлся для них не только сугубо интимным, но и болезненным (Сборник законов 1956: 402; ГАВО: Ф. Р-3969. ОП. 7. Д. 117. Л. 44-45; ОП. 11. Д. 49. Л. 193; Оп. 12. Д. 18. Л. 32-33). Внебрачные связи со стороны женщин являлись одной из стабильных причин к прерыванию беременности. Например, в конъюнктурном обзоре гинекологического отделения 9-й больницы конца 1962 г. на четвертом месте среди причин к аборту числились внебрачные связи, что составляло 6,6\% от общего количества абортов. Стоит отметить, что женщины признавались в поступке, указывая именно данную причину (а не какую-либо иную), рассчитывая, прежде всего на конфиденциальность информации (ГАВО: Ф. Р-3969. Оп. 11. Д. 47. Л. 159). Если применение передовых средств контрацепции (пероральные, внутриматочные) в середине 1960-х гг. оставалось чуждым и для населения столицы, то не предстает удивительным, что аборт для нестоличных горожанок оставался самым распространенным способом контрацепции (Белова, Дарский 1972: 135-136). Дешевле, и как казалось женщинам проще, было сделать спринцевание раствором мыльным или марганца, однако такие методы нередко влекли за собой серьезные последствия для здоровья (ГАВО: Ф. Р-3969. Оп. 7. Д. 117. Л. 47-49). А имеющиеся механические средства контрацепции были недоступны для большинства населения малого города, о чем вспоминают респондентки (ПМА: Н.Е.; Е.В.; А.И.).

Даже в письмах для себя (дневники 3.С. Седельниковой) женщина описывала интимную близость с мужчинами осторожно, будто стыдясь своих чувств, и открыто показывая свое «непозволительное» поведение: «Иногда, когда его дыхание выдает волнение я ловлю его руку на своем бедре или животике. Я тот час же затихаю, как бы прислушиваясь, и он понимает, что сделал непозволительный жест. Иногда он ласкает осторожно мою грудь, мне приятно и стыдно... я отнимаю руку, а иногда затихаю... нехорошо? Ну и пусть!» - записала тридцатидевятилетняя женщина в дневнике об отношениях с будущим мужем (ГАВО: Ф. Р-6880. Оп. 6. Д. 24. Л. 4). Однако о подробностях собственно сексуальной жизни женщины мы можем судить только по некоторым и достаточно редким записям в ее дневнике: «ВИ весь вечер лежал на балконе. Я разделила с ним все часы. Ласкал мою махнутку правую»; «ВИ так соскучился, что с ходу затянул к своей махнутке» - что конкретно имела ввиду женщина, можно только предположить (ГАВО: Ф. Р-6880. Оп. 6. Д. 25. Л. 17; Д. 30. Л. 153). Очевидно, что для женщины 1920 года рождения, воспитанной, вероятно, еще по старым порядкам, размышлять о сексуальной жизни (даже наедине с собой) было с моральной точки зрения просто непозволительным. Лишь дневнику женщина могла открыто рассказать о «невинных» ласках с мужчиной: «Наши отношения искренние, 
мы позволили ласкать друг друга, но все это носит совершенно невинный характер (ни намека на большую близость, кроме объятий и поцелуя, ну может быть с моей точки зрения это уж не совсем невинность), но дай бог каждому удержаться на такой “волне”, и не обидеть другого намеком на желание большего». Конечно, с будущим мужем женщине не удалось избежать и «ужасно откровенного разговора» о его допустимых и запретных действиях по отношению к ней как к женщине: «Мы с ВИ успели отдохнуть и поласкаться. Вели ужасно откровенный разговор о близости полов, и кроме всего ВИ дал слово, что ни при каких условиях не перешагнет границу наших близких отношений, сохраняя самое сокровенное на будущее! Мне снова легко, а ВИ вспотел от внутренней борьбы: “Трудную задачу вы мне дали, но раз нельзя, значит нельзя"» - записала в дневнике сорокалетняя Зинаида Седельникова (ГАВО: Ф. Р-6880. Оп. 6. Д. 24. Л. 4; Д. 25. Л. 62об). Едва ли такие подробности вспомнят, да и вряд ли расскажут респондентки в своих устных рассказах, для них эта тема остается по-прежнему запретной и сугубо интимной (в отличие, например, от женщин более молодого поколения) (Гайгес, Суворова 1990).

Если разведенная тридцатидевятилетняя врач была обеспокоена тем, что подумают соседи, которые видели, «что ко мне приходит мужчина, да и знают его. Знают и том, что все годы я одна и одна. Но что подумают?», то некоторые молодые девушки уже поколения беби-бумеров, могли вести себя откровенно развязно даже в общественных местах (ГАВО: Ф. Р-6880. Оп. 6. Д. 24. Л. 2). Конечно, такое поведение сразу же порицалось, обсуждалось и выставлялось напоказ в средствах массовой информации, прежде всего с целью нравоучительного воспитания. Например, в одной из радиопередач под названием «Поговорим о любви» обсуждали поведение некой девушки, которая «позволяла себя обнимать и целовать, причем это делалось демонстративно, на виду у всех прохожих» - с возмущением рассказывала героиня передачи об одной из своих знакомых. Любую свободу в отношениях осуждали самым ярым образом; слушательниц радиопередачи предупреждали о том, что «за последнее время в кино, литературе, на сцене театра появились этакие развинченные молодые люди, разболтанные во всем - от походки до взглядов на любовь. Подражая этим пошлякам, кое-кто стал даже поговаривать о том, что мы, дескать, созрели для новых свободных отношений в любви. Прежде всего, нового тут ничего нет. Это старый затасканный и, кстати говоря, буржуазный лозунг» (ГАВО: Ф. Р-6174. Оп. 2. Д. 451. Л. 293-294). Государство через средства массовой информации демонстративно осуждало неподобающее поведение, наставляя и предупреждая девушек и женщин о нормах допустимых и запретных в их поведении; гораздо реже наставляли юношей и мужчин, определяя ответственность за межличностные и сексуальные отношения как исключительно женскую заботу.

В газетах, предназначенных для молодежи, также можно было встретить нравоучительные высказывания. Например, в региональной молодежной газете «Молодой ленинец», статьи на тему взаимоотношений между юношей и девушкой, мужчиной и женщиной, печатались под заголовками: «Откровенный разговор», «Это не личное дело», «О самом сокровенном», «Очень личное» или вовсе «Разговор на “запретную” тему» (Молодой ленинец 1953: 17 января, 21 июня; Молодой ленинец 1964: 26 января, 29 ноября; Молодой ленинец 1965: 12 января, 28 июля). в газете Волгоградская (Сталинградская) правда - это была рубрика «На темы воспитания» (Волгоградская правда 1965: 7 апреля). в большинстве рассказов главными героями 
являлись еще неженатые пары или уже супруги, однако виноватыми в различных ситуациях оказывались именно женщины - невнимательные и легкомысленные.

В браке жены и мужья едва ли разговаривали о нюансах интимной жизни, о чем рассказала одна из информанток: «Вот интересно, если бы в то время прочитать книги, которые есть сейчас, хоть дать своим мужьям, может они бы по-другому немножко смотрели на все это. Вот настолько мы были стеснительными, вот настолько мы были недотроги, считали все это зазорным, неприличным» (ПМА: М.Ф.). Повинуясь собственным желаниям или прихотям мужчин, женщины расплачивались собственным здоровьем, делая множественные аборты; на наш взгляд, именно недомолвки и стеснения самих женщин, а также недостаточный уровень просветительской агитации, являлись первопричиной отсутствия контроля интимной жизни как внутри, так и вне семьи (многодетность женщин, высокая абортируемость). Все эти вопросы остаются открытыми, и ответы на них мы можем найти лишь в голосах жительниц и жителей города, которые, однако, очень редко с охотой идут на такие откровенные разговоры.

По замечаниям социологов того времени - брак «представляет собой исторически сложившуюся форму отношений между полами», который государство должно было непременно регулировать и направлять в нужное русло. в свою очередь, «только зарегистрированный брак порождает права и обязанности супругов» (Кодекс законов о браке 1961: 5). Власти считали, что семья «немыслима без радости отцовства и материнства» и важную роль в этом играл общественный характер воспитания (Харчев 1955: 4, 65). Горожанки и горожане региона видели в государстве определенные рычаги, при помощи которых можно было воздействовать на неугодного или аморально действующего благоверного/благоверную. Потому нередкими были обращения жителей в городской комитет КПСС, а также в первичные партийные организации предприятий с жалобами на спутников жизни. Отчаявшиеся супруги были готовы не только рассказать, но и в подробностях описать поступки друг друга, лишь бы сохранить семью. Большинство выявленных нами писем и жалоб принадлежали именно женщинам, которые с эмоциями и в мелочах описывали свое бедственное положение (ЦДНИВО: Ф. 71. Оп. 21, 23, 25, 34, 37). Редкими были обращения мужчин, однако поразило подробностью письмо одного из них: «После новогоднего вечера, собираясь ехать домой, я поджидал свою жену у автобуса во дворе нашего управления, которая ушла за сумочкой в контору. Т. Богатырев пошёл за ней следом и там он стал обнимать мою жену и говорить ей, что она ему нравится и полез ее целовать»; указав в конце письма: «Прошу вас разобраться в моем заявлении и по партийному со всей душой отнестись к этому делу» (ЦДНИВО: Ф. 71. Оп. 21. Д. 41. Л. 1об, Л. 2Аоб). Это лишь небольшие выдержки из подробного письма, написанного на трех тетрадных листах. Для мужчины данная жалоба являлась криком души и отчаянным шагом, а государство он считал единственным путем воздействия на виновника и мерой к сохранению семьи.

Женщины чаще мужчин обращались с подобными письмами за помощью, они жаловались на бесчинства как сожителей, так и мужей. Например, в 1960 г. женщина жаловалась на недостойное поведение своего сожителя, который узнав о ее беременности «бросил ее и отказался от сына». Одинокая женщина, находившаяся не только в тяжелой материальной, но и жилищной ситуации, пыталась привлечь мужчину к ответственности и добиться выплаты алиментов, однако в горкоме ей сообщили о том, что «юридически Л. нельзя заставить оказывать помощь ребенку», в связи с 
чем жалоба безоговорочно была снята с контроля. Поступок мужчины был признан аморальным, однако одинокую мать власти поддержали только денежным пособием в размере 50 рублей в месяц (Сборник законов 1956: 389-390; ЦДНИВО: Ф. 71. Оп. 34. Д. 29. Л. 3-5). Подчеркивая факт незаконности отношений (отсутствие заключения брака), государство нравоучительно проучило женщину, фактически не оказав ей никакой помощи, оставив в стороне и ее просьбу о решении жилищного вопроса. в городской комитет жаловалась и гражданка М., которую муж бросил с 8 детьми. Не только отсутствие мужа, но и внезапное его возвращение, сопровождаемое хулиганским поведением (проживание без прописки в ее доме, драки, кража вещей), заставило женщину раскрыть подробности несчастной семейной жизни. Однако в ходе расследования жалобы, проверяющие не нашли оснований к тому, чтобы привлечь гражданина к ответственности, и пришли к выводу о том, что «в разладе семейной жизни они виноваты оба» и в своих отношениях они должны разобраться самостоятельно (ЦДНИВО: Ф. 71. Оп. 34. Д. 29. Л. 162-163). Судьба женщины осталась нам неизвестной; можно только предположить, сумела ли многодетная мать добиться развода с мужем или же продолжила терпеть его хамское поведение. Милиция предпочитала не вмешиваться в семейные дела, а потому женщинам более ничего не оставалось делать, как пытаться воздействовать на мужей общественными мерами через городской комитет и партийную организацию. Но если мужчины и подвергались какому-либо наказанию, то первичные организации предприятий предпочитали ограничиваться личными беседами, предупреждениями, а в редких случаях исключением из партии и увольнением с работы (ЦДНИВО: Ф. 71. Оп. 34. Д. 29. 98-99, 103; Оп. 37. Д. 66. Л. 312). Едва ли такие меры действительно могли разрешить семейные проблемы, ведь в тяжелейшей ситуации оставались именно женщины, которые были вынуждены продолжать воспитывать детей, сожительствовать и вести общий быт с мужьями, демонстрирующими аморальное поведение. в большинстве случаев их голоса оставались неуслышанными, а минимальные меры воздействия на виновных не решали всех существовавших проблем.

Подробностями семейных неурядиц женщины делились с подругами и знакомыми, например, врач 3.С. Седельникова выслушивала немало историй о несчастьях в личной жизни: «Вчера Инна Александровна поделилась со мной своими переживаниями. Муж устроил ей скандал за посещение одной кинотеатра - и дело дошло до оскорблений»; «Ек. Павловна рассказала мне, что Гриша снова устроил скандал Зиночке и бил ее. Переживает и советуется, как быть. Ну, я уже свое сказала. Никогда нельзя прощать физическое оскорбление. Никогда!»; «Была Дуся с Верой (Вера с синяком под правым глазом - нахамил Василий, вчера избил). Дала ей направление в 11-ю больницу, угостила их отварным картофелем с селедкой и чаем»; «Вчера ВИ вернулся в 10 ч. страшно расстроенным - у Люды и Левы крупный скандал, окончился тем, что Люда с Андреем ушли ночевать к матери, Лева напился и вел себя, как хулиган - бил мебель, оскорблял Люду и даже ударил!... Ужас!» (ГАВО: Ф. Р-6880. Оп. 6. Д. 14. Л. 12; Д. 15. Л. 168об; Д. 32. Л. 60; Д. 35. Л. 39). Домашнее насилие выступало скрытой проблемой советской семьи, ведь органы власти предпочитали не вмешиваться в семейные разборки, а женщины, которые являлись объектом насилия, нередко стеснялись происшествия, рассказывая о проблемах друг другу, чтобы хоть как-то справиться с потрясением.

Не все женщины решались на развод, многие продолжали терпеть измены, оскорбления и нанесение увечий, но даже избавление от тягот такого брака нередко нано- 
сило сильное моральное потрясение разведенным женщинам: «Я выслушала подробности размолвки с мужем. Она совсем не знала этого человека, познание пришло в момент супружества, причинив массу страданий. Этот мужчина оказался на редкость противоположным ей человеком - черств, скуп, и самое главное, абсолютно лишенным чуткости и внимания. Чувствуется, что она уже оправилась от удара, но след сильный». Многие мужчины не знали элементарных правил не только любезного, но и приличного отношения к своим женам на глазах общественности, об одной из таких супружеских пар с негодованием написала женщина-врач: «Вечер провели у Смирновых. Неприятное впечатление от привычной грубости Валентина Николаевича с женой. Таня то краснеет, то не замечает, то немного его одернет. Обидно за Таню. Я высказала это ВИ, он почему-то промолчал, хотя и сам раньше говорил об этом»; «Я наставила Валентина Николаевича за черствость не иметь привычки дарить жене подарки, даже поздравлять, ему все же было стыдно, авось что-то изменится. А Таню жаль, не завидую ее жизни, она хорошая мать, жена и женщина» (ГАВО: Ф. Р-6880. Оп. 6. Д. 26. Л. 20, 34, 169). Сама женщина-врач в тридцатилетнем возрасте развелась с мужем после трех лет совместной жизни; будучи инициатором развода, она переехала в Сталинград (Волгоград), где и начала новую жизнь. в отличие от многих других женщин, она не желала терпеть измены, пьянство и неуважение со стороны мужа (ГАВО: Ф. Р-6880. Оп. 6. Д. 13. Л. 52, 52об, 54об). Следует только предположить, какая обстановка могла царить в менее обеспеченных семьях. Такую непростую ситуацию в семье описала одна из информанток: «Отец издевался над матерью, она подала на развод. Это была мамина инициатива, он бы ее добровольно никогда не отпустил. Она собрала два чемодана, меня и уехала» - эти события женщина запомнила, будучи еще девятилетней девочкой (ПМА: Е.В.).

«После свадьбы» - с таким заголовком в газете «Молодой ленинец» печатались статьи на тему брачно-семейных отношений (Молодой ленинец 1967: 13 января). в одной из таких статей 1967 г. обсуждалась тема бракоразводного процесса; среди причин к разводу отмечались злоупотребление алкоголем (со стороны мужчин) и несходство характеров. Был приведен показательный пример, когда в семье работающая женщина не успевала мужу приготавливать ужин, и тот нередко был вынужден питаться в столовых и кафе, в которых «выпить сам бог велел»; обвиняли в этой ситуации женщину, потому как именно ей «должна принадлежать инициатива в ведении домашнего хозяйства». Немногие мужчины помогали своим женам с домашними делами; повезло врачу 3.С. Седельниковой, муж которой мог разделить с ней абсолютно любые домашние хлопоты: «Домой пришла в начале 3-го, ВИ обтирал полы в балконе, в комнате чисто, в кухне приготовлен обед - борщ и бефстроганов...»; «После обеда я задумала стирать и кончила в 8 ч. Милый как всегда помогал, полоскать и вешал. Устала ужасно» - едва ли каждая женщина могла похвастаться такими поступками со стороны мужа (ГАВО: Ф. Р-6880. Оп. 6. Д. 30. Л. 151; Д. 28. Л. 162). Опрошенные нами женщины отметили, что домашние дела выступали все-таки женской заботой, им помогали дети, преимущественно дочери, реже сыновья или мужья (ПМА: И.В.; М.Ф.; Л.Д.). Да и в средствах массовой информации очень редко можно было встретить заметки о том, что мальчики и мужчины разделяют или должны разделять с хозяйками домашний труд (Молодой ленинец 1954: 5 октября); данная прерогатива закрепилась исключительно за женщинами, о чем им постоянно напоминалось (Сталинградская правда 1954: 10 января, 7 июля; Сталинградская правда 1956: 11 марта; Сталинградская правда 1960: 28 января; Волгоградская правда 1963: 2 
ноября). «Неравномерность домашних нагрузок», о которой социологи впервые заговорили в 1960-е гг. заняла прочное место в семейной жизни провинциальных горожан, что не только приводило к дискриминации одного из супругов, но и хронической усталости женщин, нередко вынужденных не только работать, но и «держать» на себе дом (уборка, приготовление пищи, воспитание детей) (Грушин 1967; Гордон, Клопов 1972: 100).

Инициатором развода мог быть как мужчина, так и женщина, однако общественность непременно об этом узнавала, потому как сведения о «возбуждении дела о разводе» обязательно размещались на последней полосе региональной газеты, кроме полных имен участников процесса, сообщалось место их жительства, что позволяло совершенно точно определить личность разводящихся; объявление такого же характера о собственном разводе Зинаида Седельникова памятно вклеила в дневник (Сталинградская правда 1954: 5 января, 6 января; Волгоградская правда 1962: 27 февраля; ГАВО: Ф. Р-6880. Оп. 6. Д. 13. Л. 54-55). Публичная процедура развода посредством народного суда выступала своеобразным барьером на пути разводящихся, ведь одной из главных задач такого суда являлось возможное примирение супругов (Кодекс законов о браке 1961: 9-10). Однако, как правило, супружеские пары добровольно шли на судебное дело уже в крайнем случае, когда ситуация становилась безвыходной. Многих останавливала боязнь одиночества, а кто-то стеснялся публичной огласки: «В 7-м часу приехала Авуся. Выглядит хорошо, поправилась, но еще сдерживает слезы, рассказывает о эгоизме и периодической грубости Юрия. Два года он на ее иждивении (приносит 30-40 руб. в месяц, работая в горгазе), опять в этом году провалила на вступительный экзамен в институт. Она получает 80 р. Двоим этих денег хватает только на питание (а он вечно чувствует себя голодным). Себе Авуся абсолютно ничего не покупает. Вот вам и замужество! И теперь удерживает только “боязнь пересудов” (ГАВО: Ф. Р-6880. Оп. 6. Д. 30. Л. 152об, 153). Однако именно в разводе государство нередко видело путь к разрешению семейных проблем: в этом случае одинокая мать получала пособие или алименты от бывшего мужа, правда, последнее обязательство не всегда соблюдалось; в надежде установить справедливость женщины подавали жалобы в горком КПСС (ЦДНИВО: Ф. 71. Оп. 34. Д. 29. Л. 143-144). Но некоторые горделивые и самостоятельные матери пытались даже отказываться от положенных выплат, о чем рассказала одна из респонденток: «Развелась через год, ушла к родителям вместе с ребенком. Сначала я отказывалась от алиментов, но потом муж регулярно платил алименты, 25 процентов до совершеннолетия сына. Потом из-за рождения у него ребенка в новом браке, уменьшили выплаты на одну треть. Так вот и прожила всю жизнь одна» (ПМА: И.В.).

Низкая грамотность женщин в вопросах полового воспитания имела множество последствий, среди которых внебрачные беременности, многодетность, высокая абортируемость, нередко заканчивающаяся смертельными исходами. Женщины довоенного поколения, воспитанные во многом еще по дореволюционным порядкам, в вопросах интимной близости были крайне стеснительными и аккуратными, чего нельзя было сказать о поколении беби-бумеров. Исподволь власти вмешивались в семейную жизнь горожан, потому как «регистрация брака устанавливается как в интересах государственных и общественных, так и с целью личных и имущественных интересов супругов и детей» (Кодекс законов о браке 1961: 5). в свою очередь в государстве горожане видели рычаги давления, при помощи которых можно было воздействовать на неблагоприятную семейную обстановку. Немногие женщины были счастливы в браке, 
этому сопутствовало неподобающее поведение мужей (пьянство, грубость, измены), а публичность бракоразводного процесса являлась своеобразным препятствием на пути разводящихся сторон. в реальной жизни данные меры действительно останавливали некоторых горожанок, боявшихся «пересудов». Несмотря на некоторую вольность в сексуальном поведении послевоенного поколения, преобладающим оставался уклад, согласно которому интимная жизнь продолжала тщательно скрываться от общественности; «неприличная тема» демонстрировалась в средствах массовой информации лишь с нравоучительными целями, поучая, однако именно женскую половину населения. Нестоличный регион, который с опозданием принимал передовые идеи (важность полового воспитания, применение и обеспечение доступности средств контрацепции), вносил немало коррективов в жизни горожанок.

\section{Источники и материалы}

Ананьев 1954 - Ананьев Я.М. Гигиена женщины. Сталинград: Сталинградское книжное издательство, $1954.96 \mathrm{c}$.

Ананьев 1967 - Ананьев Я.М. Гигиена женщины. Волгоград: Нижне-Волжское книжное издво, $1967.64 \mathrm{c.}$

Волгоградская правда 1962 - Волгоградская правда. 1962. 27 февраля.

Волгоградская правда 1963 - Волгоградская правда. 1963. 2 ноября.

Волгоградская правда 1965 - Волгоградская правда. 1965. 7 апреля.

ГАВО Ф. Р-6880 - Государственный архив Волгоградской области (ГАВО). Коллекция документов медицинских работников. Ф. Р-6880. Оп. 6.

ГАВО Ф. Р-3969 - Государственный архив Волгоградской области (ГАВО). Отдел здравоохранения исполнительного комитета Волгоградского городского Совета народных депутатов (горздравотдел). Ф. Р-3969. Оп. 7, 11.

ГАВО Ф. Р-6174 - Государственный архив Волгоградской области (ГАВО). Волгоградский комитет по радиовещанию и телевидению. Ф. Р-6174. Оп. 2.

Гранат 1965 - Гранат Н.Е., Матвеева Е.Е. Девочка, девушка, женщина. М.: Знание, 1965. 63 с. Добровольский 1953 - Добровольский Н. Большая любовь // Работница, 1953. № 6. С. 25-28. Демезер, Дзюба 1956 - Демезер А.А., Дзюба М.Л. (сост.) Домоводство. М.: Сельхозгиз, 1956. 480 с. Демезер, Дзюба 1958 - Демезер А.А., Дзюба М.Л. (сост.) Домоводство. М.: Сельхозгиз, 1958. 559 с. Мартемьянова 1965 - Мартемьянов В.А. (под ред.) Домоводство. М.: Колос, 1965. 759 с.

За здоровый быт 1956 - За здоровый быт. Л.: б.и., 1956. 200 с.

За здоровый быт 1960 - За здоровый быт. Л.: б.и., 1960. 274 с.

Карбовская 1962 - Карбовская В. Встреча с Любовью // Работница, 1962. № 1. С. 26.

Кодекс законов о браке 1961 - Кодекс законов о браке, семье и опеке РСФСР. М.: Госюриздат, 1961. $200 \mathrm{c}$.

Коммунистическая партия Советского Союза 1986 - Коммунистическая партия Советского Союза в резолюциях и решениях съездов, конференций и пленумов ЦК (1898-1986). Т. 9. 1956-1960. М.: Политиздат, 1986. 574 с.

Кононенко 1955 - Кононенко Е. Откровенный разговор // Работница, 1955. № 7. С. 25. Коробкевич 1960 - Коробкевич О. Вам, девушки. М.: Медгиз, 1960. 272 с.

Молодой ленинец 1953 - Молодой ленинец 1953. 17 января, 21 июня.

Молодой ленинец 1954 - Молодой ленинец 1954. 5 октября.

Молодой ленинец 1956 - Молодой ленинец 1956. 30 декабря.

Молодой ленинец 1958 - Молодой ленинец 1958. 5 июля.

Молодой ленинец 1964 - Молодой ленинец 1964. 26 января, 29 ноября.

Молодой ленинец 1965 - Молодой ленинец 1965. 12 января, 28 июля.

Молодой ленинец 1967 - Молодой ленинец 1967. 13 января. 
Народное хозяйство 1967 - Народное хозяйство Волгоградской области за 50 лет. Статистический сборник. Волгоград: Ниж.-Волж. кн. изд-во, 1967. 263 с.

Николаева 1962 - Николаева Л. Любовью дорожить умейте. Обзор писем // Работница, 1962. № 10. C. 28-30.

Никончик 1965 - Никончик О.К. Пусть женщина решает сама // Здоровье, 1965. № 5. С. 17-18. ПМА - Полевые материалы автора, г. Волгоград. 2019-2020 гг. (информанты -Мария Федоровна 1932 г.р.; Ираида Васильевна 1937 г.р.; Лилия Ивановна 1939 г.р.; Нина Петровна 1941 г.р.; Елена Васильевна 1944 г.р.; Нина Евгеньевна 1945 г.р.; Татьяна Викторовна 1948 г.р.; Антонина Ивановна 1948 г.р.; Людмила Дмитриевна 1948 г.р.; Галина Юрьевна 1951 г.р.; Ольга Владимировна 1953 г.р.; Елена Валентиновна 1960 г.р.).

Сборник законов 1956 - Сборник законов СССР и указов Президиума Верховного Совета СССР (1938-июль 1956 гг.). М.: Госюриздат, 1956. 500 с.

Сталинградская правда 1954 - Сталинградская правда 1954. 5 января, 6 января, 10 января, 7 июля. Сталинградская правда 1956 - Сталинградская правда 1956. 11 марта.

Сталинградская правда 1960 - Сталинградская правда 1960. 28 января.

Стерин 1962 - Стерин В. Любовь есть, Нина! // Работница, 1962. № 2. С. 12-14.

Тарасовой 1962 - Тарасовой Е. Свадебный дворец // Работница, 1962. № 1. С. 21.

ЦДНИВО Ф. 71 - Центр документации новейшей истории Волгоградской области (ЦДНИВО). Волгоградский городской комитет КП РСФСР. Ф. 71. Оп. 21, 34.

\section{Научная литература}

Белова И.А., Дарский Л.Е. Статистика мнений в изучении рождаемости. М.: Статистика, 1972. $144 \mathrm{c}$.

Богданович Л. Организация полового воспитания подростков // Вопросы сексопатологии. М.: Мин. здравоохранения РСФСР, 1969. С. 5-6.

Гайгес А., Суворова Т. Любовь - вне плана. М.: Собеседник, 1990. 248 с.

Голод С. Отчет читателю. Об индивидуальной сексуальной свободе // Наука и техника (Рига), 1969. № 11. С. 32-33.

Голод С.И. ХХ век и тенденции сексуальных отношений в России. СПб.: Алетейя, 1996.191 с.

Голод С.И. Семья и брак: историко-социологический анализ. СПб.: ТОО ТК «Петрополис», 1998. $272 \mathrm{c}$

Гордон Л.А., Клопов Э.В. Человек после работы. Социальные проблемы быта и внерабочего времени. М.: Наука, 1972. 268 с.

Грушин Б.А. Свободное время: Актуальные проблемы. М.: Мысль, 1967. 175 с.

Емельянова Т.П., Шмидт Д.А. Романтические отношения и брак в социальных представлениях поколений миллениалов и бэби-бумеров // Вестник Московского государственного областного университета, 2019. № 1. С. 29-43.

Здравомыслова Е.А., Темкина А.А. Государственное конструирование гендера в советском обществе // Журнал исследований социальной политики, 2003. Т. 1. № 3-4. С. 299-321.

Кон. И.С. Половая мораль в свете социологии // Советская педагогика, 1966. № 12. С. 64-77.

Кон И.С. Сексуальная культура в России: «клубничка» на березке. М.: О.Г.И., 1997. 459 с.

Кон И.С. Клубничка на березке. Сексуальная культура в России. М.: Время, 2010. 606 с.

Лебина Н.Б. Мужчина и женщина: тело, мода, культура. СССР - оттепель. М.: НЛО, 2014. 208 с. Миненко Г.Н., Жилянина Н.А. Культура советской городской семьи в 1945-1970-х годах // Вестник Кемеровского государственного университета культуры и искусств, 2020. № 53. С. 173-179.

Пушкарева Н.Л. Феминология и «история женщин» в контексте проблем гуманитарного знания // Женщины России на рубеже 20-21 веков. Материалы международной научной конференции. Ивановский государственный университет. Иваново, 23-24 апреля 1998 г. Иваново: Юнона, 1998. С. 8-13.

Пушкарева Н.Л. Историческая феминология, женская и гендерная история: итоги и перспек- 
тивы // Женщина в российском обществе, 2002. № 2-3. С. 32-37.

Пушкарева Н.Л. Гендерная система советской России и судьбы Россиянок // Новое литературное обозрение, 2012. № 5 (117). С. 8-23.

Пушкарева Н., Белова А., Миџюк Н. Сметая запреты: очерки русской сексуальной культуры

XI-XX веков. М.: Новое литературное обозрение, 2021. 504 с.

Темкина A.A. К вопросу о женском удовольствии: сексуальность и идентичность // Мишель Фуко и Россия / под ред. О. Хархордина. СПб., М.: ЕУСПб, Летний Сад, 2001. С. 316-345.

Темкина A.A. Новый быт, сексуальная жизнь и гендерная революция // Новый быт в современной России: гендерные исследования повседневности / под ред. Е. Здравомысловой, А. Роткирх, А. Темкиной. СПб.: Издательство Европейского университета в Санкт-Петербурге, 2009. С. 33-67.

Харчев А.Г. Брак и семья в советском обществе. Л.: Ленинградское газетно-журнальное и книжное издательство, 1955. 89 с.

Харчев А.Г. Брак и семья в СССР. М.: Мысль, 1964. 325 с.

Шевченко Э. Задачи основ полового воспитания среди дошкольников // Вопросы сексопатологии. М.: б.и., 1969. С. 14-15.

Kon I. Sex and Russian society. Bloomington; Indianapolis: Indiana univ. press, 1993. 168 p.

Bogdashina, Irina $V$.

Intimate Experiences in Women's Ego-Documents of the 1950s - 1960s: New and Traditional in the Models of Sexual Behavior of Soviet Women from a Non-Capital City

\section{DOI: 10.33876/2311-0546/2021-4/174-190}

The article examines the relationship between male and female residents of Volgograd (Stalingrad), a large but non-capital city, in the 1950s - 1960s. The study aims to identify the behavioral patterns of urban women in dating relationships based on the use of egodocuments. The research methodology includes the empathy method, comparative historical and biographical methods. The study is based on ego documents (diaries, letters, oral history), periodicals (magazines, newspapers), popular science literature (brochures, manuals), regulations (decrees, ordinances). The article reveals the urban women's notions about intimate life, which they often hid from the public in the studied period. The authorities gradually interfered in the family people's family life, forming the sexual culture of the population. Scarce exposure of women to sex education resulted in extramarital pregnancies, high abortion rates, and multiple children. Inappropriate husbands' behavior (alcohol abuse, rudeness, cheating) was still common in marriage, and the publicity of the divorce proceedings was an obstacle for divorcing spouses. Therefore both men and women saw party organs as leverage to resolve family troubles. Despite the seeming liberty of the postwar generation, intimate life was still mainly hidden from the public. The "taboo subjects" were only discussed in the mass media in a moralistic way for the sake of education of the female population. However, living conditions in a non-capital city, which was belatedly adopting progressive ideas (the importance of sex education), led to consequent changes in the lives of urban women.

Keywords: dating relations, gender anthropology, intimate everyday practices, Khrushchev's "thaw", Volgograd

For Citation: Bogdashina, I.V. 2021. Intimate Experiences in Women's Ego-Documents of the 1950s - 1960s: New and Traditional in the Models of Sexual Behavior of Soviet Women from a Non-Capital City. Herald of Anthropology (Vestnik Antropologii) 4: 174-190. 
Author Info: Bogdashina, Irina V. - Volgograd state University, Mikluho-Maklay Institute of Ethnology and Anthropology RAS (Moscow, RF). E-mail: ira18bogdashina@mail.ru

Funding: The research is published as part of the Research Plan of the Institute of Ethnology and Anthropology RAS and was carried out with the financial support of the Russian Foundation for Basic Research, scientific project No. 19-09-00191

\section{References}

Belova, I.A., and L.E. Darskij. 1972. Statistika mnenij v izuchenii rozhdaemosti [Opinion statistics in the study of fertility]. Moscow: Statistika.

Bogdanovich, L. 1969. Organizaciya polovogo vospitaniya podrostkov [Organization of sex education for adolescents]. Voprosy seksopatologii. Moscow: Min. zdravoohraneniya RSFSR.

Emeliyanova, T.P., and D.A. Shmidt. 2019. Romanticheskie otnosheniya i brak v social'nyh predstavleniyah pokolenij millenialov i bebi-bumerov [Romance and marriage in the social perceptions of millennials and baby boomers]. Vestnik Moskovskogo gosudarstvennogo oblastnogo universiteta 1: 29-43.

Gajges, A., and T. Suvorova. 1990. Lyubov'-vne plana [Love is out of plan]. Moscow: Sobesednik.

Golod, S. 1969. Otchet chitatelyu. Ob individual'noj seksual'noj svobode [Report to the reader. On individual sexual freedom]. Nauka i tekhnika (Riga) 11: 32-33.

Golod, S.I. 1996. XX vek i tendencii seksual'nyh otnoshenij v Rossii [XX century and tendencies of sexual relations in Russia]. St. Petersburg: Aletejya.

Golod, S.I. 1998. Sem 'ya i brak: istoriko-sociologicheskij analiz [Family and marriage: a historical and sociological analysis]. St. Petersburg: TOO TK «Petropolis».

Gordon, L.A., and E.V. Klopov. 1972. Chelovek posle raboty. Social'nye problemy byta $i$ vnerabochego vremeni [Man after work. Social problems of everyday life and non-working time]. Moscow: Nauka.

Grushin, B.A. 1967. Svobodnoe vremya: Aktual'nye problemy [Free time: Actual problems]. Moscow: Mysl'.

Harchev, A.G. 1955. Brak i sem'ya v sovetskom obshchestve [Marriage and family in Soviet society]. Leningrad: leningradskoe gazetno-zhurnal'noe i knizhnoe izdatel'stvo.

Harchev, A.G. 1964. Brak i sem 'ya v SSSR [Marriage and family in the USSR]. Moscow: Mysl'.

Kon, I.S. 1966. Polovaya moral' v svete sociologii [Sexual morality in the light of sociology]. Sovetskaya pedagogika 12: 64-77.

Kon, I.S. 1997. Seksual'naya kul 'tura v Rossii: «klubnichka» na berezke [Sexual culture in Russia: "strawberry" on a birch tree]. Moscow: O.G.I.

Kon, I.S. 2010. Klubnichka na berezke. Seksual'naya kul'tura v Rossii [Strawberry on a birch. Sexual culture in Russia]. Moscow: Vremya.

Lebina, N.B. 2014. Muzhchina i zhenshchina: telo, moda, kul'tura. SSSR - ottepel' [Man and woman: body, fashion, culture. USSR - thaw]. Moscow: NLO.

Minenko, G.N., and N.A. Zhilyanina. 2020. Kul'tura sovetskoj gorodskoj sem'i v 1945-1970$\mathrm{h}$ godah [The culture of the Soviet urban family in the 1945-1970s]. Vestnik Kemerovskogo gosudarstvennogo universiteta kul 'tury i iskusstv 53: 173-179.

Pushkareva, N.L. 1998. Feminologiya i «istoriya zhenshchin» v kontekste problem gumanitarnogo znaniya [Feminology and "history of women" in the context of the problems of humanitarian knowledge]. Zhenshchiny Rossii na rubezhe 20-21 vekov. Materialy mezhdunarodnoj nauchnoj konferencii. Ivanovskij gosudarstvennyj universitet. Ivanovo, 23-24 aprelya $1998 \mathrm{~g}$. Ivanovo: Yunona.

Pushkareva, N.L. 2002. Istoricheskaya feminologiya, zhenskaya i gendernaya istoriya: itogi i perspektivy [Historical Feminology, Women's and Gender History: Results and Prospects]. Zhenshchina v rossijskom obshchestve 2-3: 32-37. 
Pushkareva, N.L. 2012. Gendernaya sistema sovetskoj Rossii i sud'by Rossiyanok [The gender system of Soviet Russia and the fate of Russian women]. Novoe literaturnoe obozrenie 5 (117): 8-23.

Pushkareva, N., A. Belova, and N. Micyuk. 2021. Smetaya zaprety: ocherki russkoj seksual'noj kul'tury XI-XX vekov [Sweeping away the prohibitions: sketches of Russian sexual culture of the XI-XX centuries]. Moscow: Novoe literaturnoe obozrenie.

Shevchenko, E. 1969. Zadachi osnov polovogo vospitaniya sredi doshkol'nikov [Tasks of the basics of sex education among preschoolers]. Voprosy seksopatologii. Moscow: b.i.

Temkina, A.A. 2001. K voprosu o zhenskom udovol'stvii: seksual'nost' i identichnost' [On the question of female pleasure: sexuality and identity]. In Mishel' Fuko i Rossiya, edited by. O. Harhordina, 316-345. St. Petersburg, Moscow: EUSPb, Letnij Sad.

Temkina, A.A. 2009. Novyj byt, seksual'naya zhizn' i gendernaya revolyuciya [New way of life, sex life and gender revolution]. In Novyj byt $v$ sovremennoj Rossii: gendernye issledovaniya povsednevnosti, edited by E. Zdravomyslova, A. Rotkirh, and A. Temkina, 33-67. St. Petersburg: Izdatel'stvo Evropejskogo universiteta v Sankt-Peterburge.

Zdravomyslova, E.A., and A.A. Temkina. 2003. Gosudarstvennoe konstruirovanie gendera v sovetskom obshchestve [State construction of gender in Soviet society]. Zhurnal issledovanij social'noj politiki Vol. 1, 3-4: 299-321. 